\title{
RECUPERAÇÃO DE MATÉRIA SECA E COMPOSIÇÃO QUÍMICA DE SILAGENS DE GRAMÍNEAS DO GÊNERO Cynodon SUBMETIDAS A PERÍODOS DE PRÉ-EMURCHECIMENTO
}

\author{
Recovery of dry matter and chemical composition of Cynodon sp. stargrass silage under periods of pre-wilting
}

\author{
João Paulo Souza Quaresma', Joadil Gonçalves de Abreu², Roberto Giolo de Almeida ${ }^{3}$, \\ Luciano da Silva Cabral ${ }^{4}$, Marco Antônio de Oliveira ${ }^{5}$, Rosane Cláudia Rodrigues ${ }^{6}$
}

\begin{abstract}
RESUMO
Objetivou-se avaliar o efeito de períodos de pré-emurchecimento das gramíneas Estrela- Africana-Branca [Cynodon plectostachyus (K. Schum.) Pilg.] e Tifton 85 (Cynodon sp.) sobre algumas características de suas silagens. Utilizou-se delineamento inteiramente casualizado com dez tratamentos e três repetições. Os tratamentos foram dispostos em esquema fatorial $2 \times 5$, sendo duas gramíneas (Estrela-Africana-Branca e Tifton 85) e cinco períodos de pré-emurchecimento da forragem $(0,1,2,3$ e 4 h). As gramíneas foram cortadas aos 50 dias de rebrotação e permaneceram ensiladas por 55 dias em silos experimentais. O pré-emurchecimento promoveu aumento no teor de matéria seca da forragem cortada e da silagem das gramíneas Tifton 85 e Estrela Africana Branca. Houve diminuição nos teores de $\mathrm{N}$-amoniacal $\left(\mathrm{N}-\mathrm{NH}_{3} / \mathrm{N}\right.$-total) da silagem do capim-estrela-africana-branca, a uma taxa de 1,66 unidade percentual por hora de pré-emurchecimento, mas não houve alteração nessa variável da silagem do capim-tifton 85 . A silagem do capim-tifton 85 apresentou maior recuperação de matéria seca, maior teor de FDN e menor teor de proteína bruta do que a silagem do capim-estrela-africana-branca. $\mathrm{O}$ pH e o teor de FDA das silagens não foram influenciados pelo pré-emurchecimento.
\end{abstract}

Termos para indexação: Estrela Africana Branca, N-amoniacal, pH, teor de matéria seca, Tifton 85.

\section{ABSTRACT}

The objective of this work was to evaluate the effect of periods of pre-wilting of stargrass [Cynodon plectostachyus (K. Schum.) Pilg.] and Tifton 85 bermudagrass (Cynodon sp.) on some characteristics of their silage. Arandomized design with ten treatments and three replications was used. The treatments were arranged in a $2 \times 5$ factorial, two grasses (stargrass and Tifton 85 ) and five periods of pre-wilting of forage $(0,1,2,3$ and $4 \mathrm{~h})$. The grasses were harvested at 50 days regrowth and stored for 55 days in experimental silos. The pre-wilting caused an increase in dry matter content of forage and silage of both, Tifton 85 and stargrass. There was a decrease in the levels of ammonia- $\mathrm{N}\left(\mathrm{N}-\mathrm{NH}_{3} / \mathrm{N}\right.$-total) of the stargrass silage at a rate of 1.66 percentage unit per hour of pre-wilting, but there was no change in this variable of Tifton 85 silage. The Tifton 85 silage presented higher dry matter recovery and content of NDF and lower protein content than the silage stargrass. The $\mathrm{pH}$ and ADF content of the silage were not affected by prewilting.

Index terms: dry matter content, $\mathrm{N}$-ammonia, $\mathrm{pH}$, stargrass, Tifton 85 bermudagrass.

(Recebido em 31 de janeiro de 2010 e aprovado em 3 de setembro de 2010)

\section{INTRODUÇÃO}

A ensilagem de forrageiras tropicais tem se tornado uma alternativa às culturas tradicionais, como o milho e o sorgo, devido ao fato de serem culturas perenes, apresentarem menor exigência de tratos culturais, de fertilidade do solo e proporcionarem maior número de cortes, que podem estar associados à rotina do manejo das pastagens empregado na propriedade.

Segundo Evangelista et al. (2000), as espécies do gênero Cynodon se destacam como opção na produção de silagem em função de serem forrageiras que se adaptam ao clima tropical e subtropical, com alto potencial produtivo, elevado valor nutritivo e excelente aceitabilidade pelos animais.

Conforme McDonald et al. (1991), a qualidade da silagem irá depender do teor de umidade, carboidratos solúveis e de sua capacidade tamponante à queda do $\mathrm{pH}$. Desta forma, a produção de silagem de forrageiras tropicais tem sido um desafio, em virtude dessas forrageiras apresentarem baixas concentrações de carboidratos solúveis, como substrato fermentescível, baixo conteúdo de matéria seca e elevado poder tampão. Essas características

\footnotetext{
${ }^{1}$ Agência de defesa sanitária Agrosilvopastoril do Estado de Rondônia - Avenida Brasil - 76999-000 - Pimenteiras do Oeste, RO - joaopsq@hotmail.com 2Universidade Federal de Mato Grosso/ UFMT - Cuiaba, MT

${ }^{3}$ Empresa Brasileira de Pesquisa Agropecuária/Embrapa - Campo Grande, MS

${ }^{4}$ Universidade Federal de Mato Grosso/UFMT - Departamento de Zootecnia e Extensão Rural - Cuiaba, MT

${ }^{5}$ Instituto Federal de Educação Ciência e Tecnologia de Rondônia - Cacoal, RO

${ }^{6}$ Universidade Federal do Maranhão - Centro de Ciências Agrárias e Ambientais/CCAA - Boa Vista - Chapadinha, MA
} 
colocam em risco o processo de conservação por meio da ensilagem, por favorecer fermentações indesejáveis, elevando as perdas quantitativas e qualitativas e limitando o consumo voluntário pelos animais (Paziani et al., 2006).

Evangelista et al. (2006) observaram que a remoção parcial de água da planta, por meio do pré-emurchecimento ou pré-secagem, garantiu vantagens operacionais na ensilagem e sobre a qualidade da silagem do capimmarandu.

Entretanto, os resultados obtidos por meio do préemurchecimento têm sido conflitantes. Castro et al. (2006b), ao avaliarem a conservação do capim-tifton 85 , observou que o pré-emurchecimento reduziu a atividade da água, o crescimento de bactérias e conseqüente intensidade da fermentação, resultando em maior estabilidade aeróbica da silagem. Porém, a desidratação excessiva da forragem a ser ensilada pode diminuir a qualidade da silagem, quando ocorre aquecimento do material, provocando a formação de compostos indigestíveis, como nitrogênio insolúvel em detergente ácido (NIDA), devido à reação de Maillard (Evangelista et al., 2004).

Neste contexto, objetivou-se avaliar o efeito de períodos de pré-emurchecimento dos capins Estrela Africana Branca (Cynodon plectostachyus (K. Schum.) Pilg.) e Tifton 85 (Cynodon sp.) sobre algumas características de suas silagens.

\section{MATERIAL E MÉTODOS}

O experimento foi conduzido na área do Centro de Pesquisa da Empresa Matogrossense de Pesquisa, Assistência e Extensão Rural - EMPAER, Cáceres-MT, situado a $16^{\circ} 09^{\prime} 02^{\prime \prime}$ Sul e $57^{\circ} 38^{\prime} 07^{\prime \prime}$ Oeste, e a altitude de $157 \mathrm{~m}$. O clima no município, segundo a classificação de Köppen, é do tipo Aw, ou seja, clima tropical, megatérmico, caracterizando-se por duas estações bem definidas: seca (abril a setembro) e chuvosa (novembro a março). O município apresenta precipitação anual média de $1.348 \mathrm{~mm}$, temperatura média anual de $25,2^{\circ} \mathrm{C}$ e umidade relativa média anual de $80,4 \%$.

O delineamento experimental utilizado foi o inteiramente casualizado com dez tratamentos e três repetições. Os tratamentos foram dispostos em esquema fatorial 2x5, sendo duas gramíneas (Estrela Africana Branca e Tifton 85) e cinco períodos de pré-emurchecimento da forragem $(0,1,2,3$ e 4 h) após o corte.

As gramíneas, Estrela Africana Branca (Cynodon plectostachyus) e Tifton 85 (Cynodon sp.) foram cortados em 08/05/2008, aos 50 dias de rebrotação, sendo o corte realizado a $5 \mathrm{~cm}$ do nível do solo. $\mathrm{O}$ corte foi efetuado às 11:00 e a forragem cortada permaneceu no campo, espalhada uniformemente em pequenas camadas, em pleno sol, de acordo com os períodos de pré-emurchecimento.

Os dados meteorológicos, no dia do préemurchecimento e ensilagem da forragem foram: precipitação pluviométrica: $0 \mathrm{~mm}$; umidade relativa do ar: $75 \%$; temperatura média: $25,3^{\circ} \mathrm{C}$; temperatura máxima: $33,7^{\circ} \mathrm{C}$; temperatura mínima: $20^{\circ} \mathrm{C}$; velocidade média do vento: $2,1 \mathrm{~m} / \mathrm{s}$.

A forragem foi ensilada em silos experimentais, não sendo realizada a repicagem do material após o corte, buscando-se assemelhar às partículas de forrageiras cortadas com equipamentos utilizados na produção de feno, gerando, neste trabalho, partículas em torno de 10 $15 \mathrm{~cm}$. Como silos experimentais utilizaram-se canos de PVC com $10 \mathrm{~cm}$ de diâmetro e $50 \mathrm{~cm}$ de comprimento com capacidade para, aproximadamente, $2,1 \mathrm{~kg}$ de forragem $\left(500 \mathrm{~kg} / \mathrm{m}^{3}\right)$. A compactação foi realizada com hastes de PVC e o fechamento com tampas de PVC dotadas de válvula tipo Bunsen, sendo as tampas lacradas com fita adesiva.

Parte do material original foi amostrado no momento da ensilagem, para posterior determinação da matéria seca, conforme Association of Official Agricultural ChemistsAOAC (1990).

A abertura dos silos ocorreu aos 55 dias após a ensilagem. Na coleta das amostras, foram desprezados os $5 \mathrm{~cm}$ da porção superior e inferior dos silos. Após esse procedimento, a silagem foi homogeneizada e dividida em duas partes. A primeira parte foi acondicionada em saco plástico e congelada para análise do teor de nitrogênio amoniacal em relação ao nitrogênio total $\left(\mathrm{N}_{-} \mathrm{NH}_{3} / \mathrm{N}-\mathrm{Total}\right)$, segundo método descrito por Nogueira et al. (2005). A outra parte da amostra foi encaminhada para pré-secagem, para posterior determinação dos teores de matéria seca (MS) e de proteína bruta (PB), conforme AOAC (1990), e dos teores de fibra em detergente neutro (FDN) e de fibra em detergente ácido (FDA), conforme metodologias descritas por Soest et al. (1991).

A avaliação do $\mathrm{pH}$ também foi realizada por ocasião da abertura dos silos experimentais, utilizando-se $9 \mathrm{~g}$ de amostra em $60 \mathrm{~mL}$ de água destilada por 30 minutos, por meio de potenciômetro digital devidamente calibrado (Silva \& Queiroz, 2002).

$O$ índice de recuperação de matéria seca (RMS) foi obtido de acordo com Jobim et al. (2007).

Os dados foram submetidos à análise de variância e de regressão, conforme metodologia descrita por Banzato \& Kronka (1992). Adotou-se o nível de probabilidade de $5 \%$ e utilizou-se o aplicativo estatístico Sisvar versão 4.6 . 


\section{RESULTADOS E DISCUSSÃO}

Houve efeito da interação espécie x período de pré-emurchecimento $(\mathrm{P}<0,05)$ para o teor de matéria seca da forragem, no momento da ensilagem. Com o aumento do período de pré-emurchecimento ocorreu aumento linear no teor de matéria seca da forragem das gramíneas Tifton 85 e Estrela Africana Branca (Tabela 1). O capimestrela-africana-branca apresentou maior taxa de secagem (3,67 unidades percentuais de matéria seca/h) em comparação ao Tifton 85 (1,70 unidade percentual de matéria seca/h), observando-se que em quatro horas de secagem, em pleno sol, o teor de matéria seca estimado do capim-tifton 85 aumentou de $34,57 \%$ para $41,37 \%$, enquanto no capim-estrela-africana-branca, o aumento no teor de matéria seca estimado, no mesmo período de secagem, foi de $29,13 \%$ para $43,82 \%$. É importante destacar que não houve revolvimento da massa de forragem durante a secagem. Com maior proporção de folhas, o capim-tifton 85 gerou uma massa de forragem mais densa, dificultando a renovação do ar no material cortado e, consequentemente, acarretando uma menor taxa de perda de umidade em relação ao capim-estrela-africana-branca.

Ao avaliar o teor de matéria seca das gramíneas dentro de cada período, observou-se que o capim-tifton 85 apresentou teores superiores nos períodos de pré- emurchecimento de 0,1 e $2 \mathrm{~h}$, igualando os teores com $3 \mathrm{~h}$, sendo que, com $4 \mathrm{~h}$, o teor de matéria seca do capim-estrelaafricana-branca foi superior (Tabela 1). Durante o processo de ensilagem, foi observada, no capim-tifton 85 , maior proporção de folhas e de material morto, reforçando o maior teor de matéria seca no momento do corte em relação ao capim-estrela-africana-branca.

Rotz \& Muck (1994), indicam um teor de matéria seca em torno de $30 \%$ no momento da ensilagem para minimizar o potencial para fermentação indesejável e produção de efluentes, reduzindo as perdas durante o armazenamento. De acordo com esses autores, no presente trabalho, o capim-tifton 85 não necessitaria de préemurchecimento, por apresentar, no momento da ensilagem, teor mínimo estimado de matéria seca de $34,57 \%$. Já o capimestrela-africana-branca, para atingir o teor mínimo estimado de $30 \%$ de matéria seca, no momento da ensilagem, teria que ser submetido a um período de pré-emurchecimento estimado de $0,23 \mathrm{~h}$.

Houve efeito da interação espécie x período de préemurchecimento no teor de matéria seca da silagem $(\mathrm{P}<0,05)$. O teor de matéria seca da silagem das duas gramíneas apresentou aumento linear em função dos períodos de pré-emurchecimento (Tabela 2).

Na silagem do capim-tifton 85 , o teor de matéria seca aumentou em 1,22 unidade percentual para cada hora de pré-emurchecimento. Na silagem do capim-estrela-

Tabela 1 - Teor de matéria seca (MS, \%) das gramíneas Tifton 85 e Estrela Africana Branca, no momento da ensilagem, em função de períodos de pré-emurchecimento.

\begin{tabular}{lcccccc}
\hline \multirow{2}{*}{ Gramínea } & \multicolumn{4}{c}{ Pré-emurchecimento (h) } & \multicolumn{2}{c}{$\begin{array}{c}\text { Equação de } \\
\text { regressão }\end{array}$} \\
\cline { 2 - 6 } & 0 & 1 & 2 & 3 & 4 & Linear $^{1}$ \\
\hline Tifton 85 & $33,13 \mathrm{~A}$ & $37,52 \mathrm{~A}$ & $38,95 \mathrm{~A}$ & $39,71 \mathrm{~A}$ & $40,54 \mathrm{~B}$ & Linear $^{2}$ \\
\hline
\end{tabular}

$\mathrm{A}>\mathrm{B}$, na coluna, pelo teste de Tukey $(\mathrm{P}<0,05)$.

${ }^{1} \mathrm{v}(\mathrm{MS}, \%)=34,568667+1,699667 \mathrm{X}(\mathrm{h})\left(\mathrm{R}^{2}=0,85 ; \mathrm{P}<0,01\right)$.

${ }^{2} \mathrm{v}(\mathrm{MS}, \%)=29,126667+3,673667 \mathrm{X}(\mathrm{h})\left(\mathrm{R}^{2}=0,93 ; \mathrm{P}<0,01\right)$.

Tabela 2 - Teor de matéria seca (MS, \%) da silagem das gramíneas Tifton 85 e Estrela Africana Branca em função de períodos de pré-emurchecimento.

\begin{tabular}{lcccccc}
\hline \multirow{2}{*}{ Gramínea } & \multicolumn{4}{c}{ Pré-emurchecimento (h) } & \multirow{2}{*}{$\begin{array}{c}\text { Equação de } \\
\text { regressão }\end{array}$} \\
\cline { 2 - 6 } & 0 & 1 & 2 & 3 & 4 & Linear $^{1}$ \\
Tifton 85 & $31,45 \mathrm{~A}$ & $35,52 \mathrm{~A}$ & $37,50 \mathrm{~A}$ & $35,37 \mathrm{~B}$ & $37,64 \mathrm{~A}$ & Linear $^{2}$ \\
\hline
\end{tabular}

$\mathrm{A}>\mathrm{B}$, na coluna, pelo teste de Tukey $(\mathrm{P}<0,05)$.

${ }^{1} \mathrm{v}(\mathrm{MS}, \%)=33,049333+1,222667 \mathrm{X}(\mathrm{h})\left(\mathrm{R}^{2}=0,60 ; \mathrm{P}<0,01\right)$.

${ }^{2} \mathrm{v}(\mathrm{MS}, \%)=27,536667+3,451333 \mathrm{X}(\mathrm{h})\left(\mathrm{R}^{2}=0,91 ; \mathrm{P}<0,01\right)$. 
africana-branca, ocorreu aumento no teor de matéria seca de 3,45 unidades percentuais para cada hora de préemurchecimento. A silagem do capim-estrela-africanabranca apresentou menor teor de matéria seca no período de pré-emurchecimento de $1 \mathrm{~h}$ em relação à do capim-tifton 85 e superou o teor de matéria seca da silagem de capimtifton 85 no período de pré-emurchecimento de $3 \mathrm{~h}$, não diferindo nos demais períodos (Tabela 2).

Os teores de FDN e de proteína bruta da silagem não foram influenciados pelo pré-emurchecimento e pela interação espécie x pré-emurchecimento $(\mathrm{P}>0,05)$, entretanto, foram influenciados pela espécie de gramínea $(\mathrm{P}<0,05)$ (Tabela 3).

Tabela 3 - Recuperação de matéria seca (RMS), teor de proteína bruta $(\mathrm{PB})$ e teor de fibra em detergente neutro (FDN) da silagem das gramíneas Tifton 85 e Estrela Africana Branca (média de cinco períodos de pré-emurchecimento).

\begin{tabular}{lccc}
\hline Gramínea & FDN (\%) & PB (\%) & RMS (\%) \\
\hline Tifton 85 & $79,45 \mathrm{~A}$ & $8,44 \mathrm{~B}$ & $91,98 \mathrm{~A}$ \\
Estrela Africana Branca & $75,60 \mathrm{~B}$ & $9,97 \mathrm{~A}$ & $86,98 \mathrm{~B}$ \\
CV (\%) & 1,77 & 8,83 & 5,99 \\
\hline
\end{tabular}

$\mathrm{A}>\mathrm{B}$, na coluna, pelo teste $\mathrm{F}(\mathrm{P}<0,05)$.

A silagem do capim-estrela-africana-branca apresentou teor de proteína bruta superior $(\mathrm{P}<0,05)$ ao observada, na silagem de capim-tifton 85 (Tabela 3). Na forragem a ser ensilada, foi observado no capim-tifton 85 , apesar do mesmo período de crescimento, maior proporção de folhas senescentes e perfilhos reprodutivos, indicando maturidade fisiológica mais avançada neste capim, característica que deve ter contribuido para os menores teores de proteína bruta observados. Evangelista et al. (2000) também não observaram efeito do pré-emurchecimento sobre o conteúdo de proteína bruta da silagem de capim-estrelaroxa, obtendo teor médio de $13,5 \%$.

Observou-se maior teor de FDN na silagem de capim-tifton $85(\mathrm{P}<0,05)$ em relação à silagem de capimestrela-africana-branca (Tabela 3). Da mesma forma que para os teores de proteína bruta, a maturidade atingida pelo capim-tifton 85 pode ter influenciado no maior teor de FDN da silagem desse capim. Evangelista et al. (2004) e Castro et al. (2006a) avaliando silagens de capim-marandu e de capim-tifton 85 , respectivamente, não observaram efeito de períodos de pré-emurchecimento sobre o teor de FDN das silagens. Comportamento contrário foi observado por Evangelista et al. (2000), que verificaram redução do teor de FDN da silagem com o aumento do teor de matéria seca do capim-estrela-roxa.

O teor de FDA das silagens também não foi influenciado pelas fontes de variação em estudo ( $\mathrm{P}>0,05)$, sendo obtido um valor médio de $45,70 \%$. O período de pré-emurchecimento a pleno sol tende a aumentar a respiração celular, diminuindo a concentração de carboidratos solúveis e aumentando o teor de FDN e FDA da forragem. No entanto, essa tendência não foi suficiente para ocasionar diferença significativa entre os tratamentos avaliados, indicando que esse comportamento não limita o uso prático do préemurchecimento. Resultados semelhantes nos teores de FDA foram observados por Castro et al. (2006a), com silagem de capim-tifton 85, e por Evangelista et al. (2000), com silagem de capim-estrela-roxa.

$\mathrm{O}$ pH da silagem não foi influenciado pelos tratamentos em estudo $(\mathrm{P}>0,05)$, sendo obtido valor médio de 4,87. Valor de pH máximo de 4,2 tem sido utilizado para indicar silagens de boa qualidade. No entanto, Jobim et al. (2007) apontam que silagens de forragens emurchecidas, geralmente, apresentam valores de $\mathrm{pH}$ acima de 4,2. Isso se deve a menor intensidade do processo de fermentação, influenciado pelo aumento da pressão osmótica, resultando em uma menor produção de ácidos (Evangelista et al., 2000), indicando que essas silagens podem atingir valores de estabilidade aeróbica com valores de $\mathrm{pH}$ mais elevados.

Castro et al. (2006b) observaram elevação do pH da silagem de capim-tifton 85 com o aumento do teor de matéria seca da forragem ensilada, com valores de 5,2 e 6,3 para os teores de matéria seca de $25 \%$ e $65 \%$, respectivamente. Resultado semelhante foi observado por Evangelista et al. (2000) em silagem de capim-estrela-roxa, ou seja, quando o teor de matéria seca na forragem ensilada aumentou de $26,3 \%$ para $41,8 \%$, o $\mathrm{pH}$ se elevou de 4,0 para 4,5 . Ao contrário dos trabalhos citados, os teores de matéria seca das forragens ensiladas podem não ter se elevado o suficiente para ocasionar diferenças significativas nos valores de $\mathrm{pH}$ das silagens no presente trabalho.

Houve efeito da interação espécie x período de préemurchecimento sobre o teor de $\mathrm{N}$-amoniacal ( $\mathrm{N}-\mathrm{NH}_{3} \%$ / $\mathrm{N}$-Total) da silagem $(\mathrm{P}<0,05)$.

Para o capim-tifton 85 , o teor de $\mathrm{N}$-amoniacal da silagem não foi afetado $(\mathrm{P}>0,05)$ pelos períodos de préemurchecimento, apresentando valor médio de 7,34\%. Para o capim-estrela-africana-branca, houve redução no teor de $\mathrm{N}$-amoniacal da silagem em 1,66 unidade percentual para cada hora de pré-emurchecimento (Tabela 4). 
Tabela 4 - Teor de $\mathrm{N}$-amoniacal $\left(\mathrm{N}-\mathrm{NH}_{3} / \mathrm{N}-\right.$ Total, \%) da silagem das gramíneas Tifton 85 e Estrela Africana Branca, em função de períodos de pré-emurchecimento.

\begin{tabular}{|c|c|c|c|c|c|c|}
\hline \multirow{2}{*}{ Gramínea } & \multicolumn{5}{|c|}{ Pré-emurchecimento (h) } & \multirow{2}{*}{$\begin{array}{c}\text { Equação de } \\
\text { regressão }\end{array}$} \\
\hline & 0 & 1 & 2 & 3 & 4 & \\
\hline Tifton 85 & $9,43 \mathrm{~A}$ & $6,83 \mathrm{~B}$ & $5,47 \mathrm{~B}$ & 7,97 A & $7,00 \mathrm{~A}$ & Não justada \\
\hline Estrela Africana Branca & $11,97 \mathrm{~A}$ & $11,10 \mathrm{~A}$ & $8,93 \mathrm{~A}$ & $7,07 \mathrm{~A}$ & $5,70 \mathrm{~A}$ & Linear $^{1}$ \\
\hline
\end{tabular}

$\mathrm{A}>\mathrm{B}$, na coluna, pelo teste de Tukey $(\mathrm{P}<0,05)$.

${ }^{1} \mathrm{v}\left(\mathrm{N}-\mathrm{NH}_{3} / \mathrm{N}-\mathrm{Total}, \%\right)=12,266667-1,656667 \mathrm{X}(\mathrm{h})\left(\mathrm{R}^{2}=0,99 ; \mathrm{P}<0,01\right)$.

Entre as gramíneas, não houve diferença $(\mathrm{P}>0,05)$ nos teores de $\mathrm{N}$-amoniacal de suas silagens, para os períodos de pré-emurchecimento de 0,3 e $4 \mathrm{~h}$, sendo que para os períodos de 1 e $2 \mathrm{~h}$, houve maior concentração de $\mathrm{N}$-amoniacal no capim-estrela-africana-branca. Esse comportamento pode estar relacionado ao aumento mais acentuado no teor de MS do capim-tifton 85 nas primeiras horas de pré-emurchecimento. Segundo Jobim et al. (2007), a redução da atividade da água em forragens emurchecidas inibe o efeito de microorganismos indesejáveis, principalmente de clostrídios, favorecendo menores teores de $\mathrm{N}$-amoniacal.

$\mathrm{O}$ teor de $\mathrm{N}$-amoniacal da silagem é um parâmetro indicativo da qualidade da silagem, considerada de alta qualidade, quando os teores de $\mathrm{N}$-amoniacal são inferiores a 10\%; indicando menor intensidade de proteólise (Soest, 1994). Dessa forma a silagem do capim-tifton 85 pode ser classificada como de alta qualidade em todos os períodos de pré-emurchecimento avaliados. Neste contexto, a silagem do capim-estrela-africana-branca apresentou teores estimados de $\mathrm{N}$-amoniacal abaixo de $10 \%$ a partir do período de pré-emurchecimento estimado de $1,37 \mathrm{~h}$.

Castro et al. (2006b) encontraram uma redução dos teores de $\mathrm{N}$-amoniacal da silagem do capim-tifton 85 com o aumento do teor de matéria seca da gramínea ocasionado, principalmente, pela restrição no crescimento de microorganismos indesejáveis.

A recuperação de matéria seca não foi influenciada pelo pré-emurchecimento e pela interação espécie x préemurchecimento $(\mathrm{P}>0,05)$, entretanto, foi influenciada pela espécie de gramínea $(\mathrm{P}<0,05)$ (Tabela 3$)$.

A recuperação de matéria seca da silagem foi maior para o capim-tifton 85 em relação ao capim-estrela-africanabranca, indicando menores perdas durante o processo fermentativo dessa silagem. A maior proporção de colmos na forragem do capim-estrela-africana-branca, observada no momento da ensilagem, aliada ao fato de não ter sido realizada a picagem do material, pode ter favorecido uma menor densidade da massa ensilada, aumentando as perdas da silagem desse capim. Segundo Paziani et al. (2006), a redução no tamanho de partículas é um procedimento indicado na ensilagem de capins tropicais pois facilita a compactação, favorecendo mais rapidamente as condições de anaerobiose na massa ensilada.

No entanto, a prática da repicagem associada ao pré-emurchecimento deve ser vista com reservas, pois a baixa eficiência na utilização da técnica e uso de equipamento inadequado pode resultar em grandes perdas a campo. Na região de condução do presente trabalho, a prática da repicagem não tem sido realizada devido à indisponibilidade de máquinas que realizem esta tarefa durante o recolhimento da forragem préemurchecida e posterior enfardamento, resultando em menores perdas a campo.

\section{CONCLUSÕES}

O aumento dos períodos de pré-emurchecimento promoveu acréscimos nos teores de matéria seca da forragem e da silagem das duas gramíneas avaliadas, sendo observado efeito benéfico do pré-emurchecimento (1,37 h) na redução do teor de $\mathrm{N}$-amoniacal da silagem do capimestrela-africana-branca. No entanto, não foi observado efeito do pré-emurchecimento sobre a recuperação de matéria seca, o pH e os teores de proteína bruta, de FDN e de FDA das silagens.

\section{REFERÊNCIAS BIBLIOGRÁFICAS}

ASSOCIATION OF OFFICIAL AGRICULTURAL CHEMISTS. Official methods of analysis. 15.ed. Arlington, 1990. 1117p.

\section{BANZATO, D.A.; KRONKA, S.N. Experimentação agrícola. 2.ed. Jaboticabal: FUNEP, 1992. 247p.}

BENACCHIO, S. Niveles de melaza em silo experimental de milho criollo (Sorghum vulgare). Agronomia

Tropical, Maracay, v.14, n.4, p.651-658, 1965. 
CASTRO, F.G.F.; NUSSIO, L.G.; HADDAD, C.M.; CAMPOS, F.P.; COELHO, R.M.; MARI, L.J.; TOLEDO, P.A. Características de fermentação e composição químico-bromatológica de silagens de capim-tifton 85 confeccionadas com cinco teores de matéria seca. Revista Brasileira de Zootecnia, Viçosa, v.35, n.1, p.7-20, 2006 a.

CASTRO, F.G.F.; NUSSIO, L.G.; HADDAD, C.M.; CAMPOS, F.P.; COELHO, R.M.; MARI, L.J.; TOLEDO, P.A. Perfil microbiológico, parâmetros físicos e estabilidade aeróbia de silagens de capim-tifton 85 (Cynodon sp.) confeccionadas com distintas concentrações de matéria seca e aplicação de aditivos. Revista Brasileira de Zootecnia, Viçosa, v.35, n.2, p.358371, 2006b.

EVANGELISTA, A.R.; ABREU, J.G.; AMARAL, P.N.C.; PEREIRA, R.C.; SALVADOR, F.M.; SANTANA, R.A.V. Produção de silagem de capim-marandu (Brachiaria brizantha Stapf cv. Marandu) com e sem emurchecimento. Ciência e Agrotecnologia, Lavras, v.28, n.2, p.443-449, 2004.

EVANGELISTA, A.R.; LIMA, J.A.; BERNARDES, T.F. Avaliação de algumas características da silagem de gramínea estrela roxa (Cynodon nlemfuensis Vanderyst). Revista Brasileira de Zootecnia, Viçosa, v.29, n.4, p.941-946, 2000.

JOBIM, C.C.; NUSSIO, L.G.; REIS, R.A.; SCHIMIDT, P. Avanços metodológicos na avaliação da qualidade da forragem conservada. Revista Brasileira de Zootecnia, Viçosa, v.36, n.6, p.101-119, 2007. Suplemento.

McDONALD, P.; HENDERSON, A.R.; HERON, S.J.E. Biochemistry of silage. 2.ed. Marlow, Chalcombe, 1991. 340p.
NOGUEIRA, A.R.A.; CASTRO, A.L.; BERNARDI, C.R.; ZANOTTO, D.L.; SOUZA, G.B.; BARROCAS, G.E.G.; CARNEIRO, H.; LIMA, J.R.; FERREIRA, J.R.; MARTINI, M.; MARTINS, N.G.; FREITAS, S.C.; BEZERRA, V.S. Análise de alimentos. In: NOGUEIRA, A.R.A.; SOUZA, G.B. (Ed.). Manual de laboratórios: solo, água, nutrição vegetal, nutrição animal e alimentos. São Carlos: Embrapa Pecuária Sudeste, 2005. v.1, p.2001-2329.

PAZIANI, S.; NUSSIO, L.; PIRES, A.; RIBEIRO, J.; ZOPOLLATTO, M.; SCHMIDT, P. Efeito do emurchecimento e do inoculante bacteriano sobre a qualidade da silagem de capim Tanzânia e o desempenho de novilhas. Acta Scientiarum. Animal Sciences, Maringá, v.28, n.4, p.393-400, 2006.

ROTZ, C.A.; MUCK, R.E. Changes in forage quality during harvest and storage. In: FAHEY JR., G.C. (Ed.) Forage quality, evaluation, and utilization. Madison: American Society of Agronomy, 1994. p.828-868.

SILVA, D. J.; QUEIROZ, A.C. Análise de alimentos: métodos químicos e biológicos. 3.ed. Viçosa, MG: UFV, 2002. 235p.

SOEST, P. J. van; ROBERTSON, J.B.; LEWIS, B.A. Methods for dietary fiber, neutral detergent fiber and nonstach polysaccharides in relation to animal nutrition. Journal of Dairy Science, Champaign, v.74, n.10, p.35833596, 1991.

SOEST, P.J. Van. Nutritional ecology of the ruminant. 2.ed. Ithaca: Cornell University, 1994. 476p. 